\title{
Prevalence and Factors Influencing Diabetic Foot Ulcer among Diabetic Patients Attending Arbaminch Hospital, South Ethiopia
}

\section{Bedilu Deribe $^{1 *}$, Kifle Woldemichael ${ }^{2}$ and Gugsa Nemera}

${ }^{1}$ Department of Nursing, Jimma University, Ethiopia

${ }^{2}$ Department of Epidemiology, Jimma University, Ethiopia

\section{Abstract}

Background: Diabetic foot ulcer is one of the long standing complications of diabetic mellitus with the life time risk up to $25 \%$. In Africa in general, particularly in Ethiopia, there are limited epidemiological studies related to diabetic foot ulcer.

Objective: The main objective of this study is to assess prevalence and factors influencing diabetic foot ulcer among diabetic patients attending Arbaminch hospital.

Methods: A cross sectional study was conducted on 216 diabetic clients attending Arbaminch hospital from Feb10, 2013 to April 10, 2013. Subjects were identified using simple random sampling and data was collected by four trained diploma level nurses using interviewer administered questioner, record review check list and observation check lists. The data was coded and entered to Epidata version 3.1 and exported to SPSS version 16.0 for analysis. Descriptive analysis was done for sociodemographic variables, diabetic knowledge, diabetes self care practice and attitude and clinical factors. Binary logistic regression analysis was also done to identify independent factors associated with diabetic foot ulcer and significant factors was declared at $p<0.05$ with $95 \%$ confidence interval. Finally data was presented with explanatory statements, tables and graphs.

Result: All of the study subjects were interviewed which gives $100 \%$ response rate with the mean \pm SD age of $50.72 \pm 13.39$ years. Out of the total 216 study subjects , about $32(14.8 \%)$ has diabetic foot ulcer, $129(59.7 \%)$ were male, $61(28.2 \%)$ from rural, $132(61.11 \%)$ were overweight, $97(44.5 \%)$ have poor diabetic foot self care practice and $80(37 \%)$ of them have secondary education. rural residence (AOR=4.074, 95\% Cl 1.262-13.151), absence of co-morbidity (AOR=0.611, 95\% Cl 0.131-0.955), mean arterial blood pressure greater than $90(\mathrm{AOR}=5.113,95 \% \mathrm{Cl}$ 1.285-20.347), duration of diabetes for more than 10years ( $\mathrm{AOR}=8.452,95 \% \mathrm{Cl} 2.365-30.994)$, are independent factor associated with DFU.

Conclusions and recommendations: Significant proportion of patients with diabetes developed diabetic foot ulcer. Rural residence; presence of co-morbidity; duration of diabetes, mean arterial blood pressure and occupation are factors associated with diabetic foot ulcer. In addition to regular diabetic care emphasis should be given on enhancing diabetic patient's knowledge of self care practice and regular diabetic foot evaluation

Keyword: Arbaminch; Diabetic foot ulcer; Prevalence

\section{Introduction}

Diabetes, considered as a disease of developed countries, is one of the endocrine disorders that reached epidemic proportions worldwide [1]. The metabolic deregulation associated with diabetes mellitus (DM) cause's secondary pathophysiologic changes in multiple organ systems that impose a tremendous burden on the individual with diabetes and on the health care system [2].

Lots of complications are associated with DM. Those complications arise chiefly from the disruption of the vascular system which can result in inadequate circulation to the peripheral body. This places the foot at higher risk of ulceration and infection [3].

As the incidence of diabetes mellitus is increasing globally, increase in complications is also unquestionable. Overall all $15 \%$ of individuals with diabetes mellitus will have foot ulcer during their lifetime and the annual incidence is $2-3 \%[4,5]$. Diabetic foot ulcer is becoming major concern of diabetic patients and those who treat them from quality of life, social and economical stand point [6].

According to the 2005 international diabetic federation report $85 \%$ of diabetes-related lower extremity amputations are preceded by a foot ulcer. In developed countries one in every six people with diabetes will have an ulcer during their lifetime and even worst in developing countries. Foot problems account for up to $15 \%$ of healthcare resources in developed countries and $40 \%$ in developing countries [2].

Among Ethiopian diabetic patients foot ulcer is major health problem. Foot ulcer associated with sepsis results in $12 \%$ of death. Low follow-up and poor glycemic control are major contributing factors. Understanding of the influential factors of foot ulcer in diabetics will enable high-risk patients to be recognized early $[7,8]$.

Even though studies showed that up to $85 \%$ of all amputation related to diabetic foot ulcer can be prevented by using simple interventions, the problem is still worsening [2]. In addition preventative strategies may become more effective if new research into how patients with diabetes

*Corresponding author: Bedilu Deribe, Department of Nursing, Jimma University, Jimma, Ethiopia, Tel: +251933220151/+251927108065; E-mail: bediluderibe2002@gmail.com

Received November 11, 2013; Accepted December 29, 2013; Published January 05, 2014

Citation: Deribe B, Woldemichael K, Nemera G (2014) Prevalence and Factors Influencing Diabetic Foot Ulcer among Diabetic Patients Attending Arbaminch Hospital, South Ethiopia. J Diabetes Metab 2: 322. doi:10.4172/2155-6156.1000322

Copyright: $\odot 2014$ Deribe B, et al. This is an open-access article distributed under the terms of the Creative Commons Attribution License, which permits unrestricted use, distribution, and reproduction in any medium, provided the original author and source are credited. 


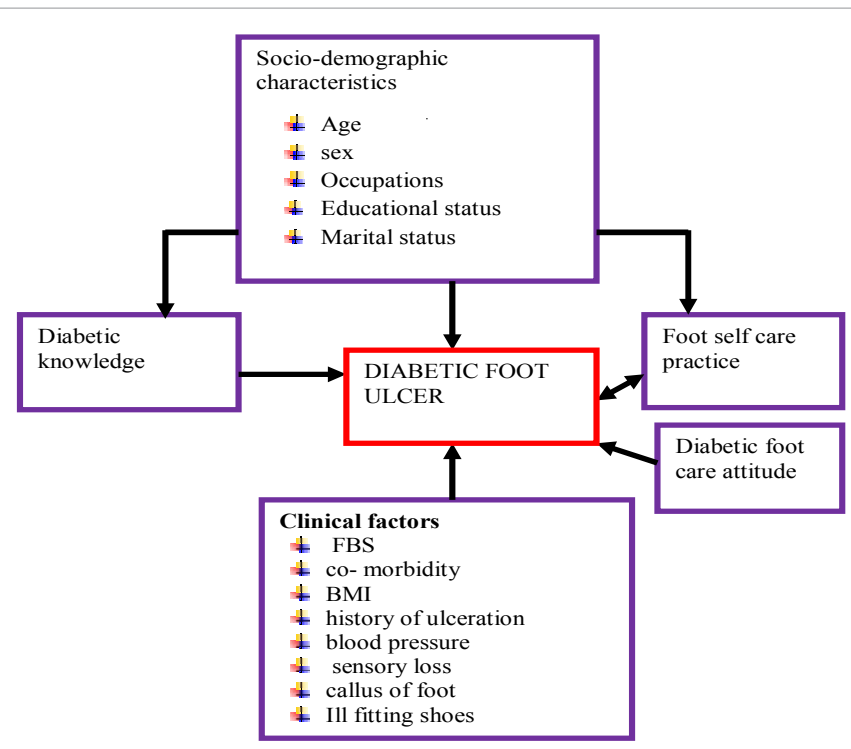

Figure 1: Conceptual frame work showing possible predictors of diabetic foot ulcer.

experience and interpret their health threats. So this study will help health educators and diabetic educators in identifying those factors influencing diabetic foot ulcer and helps diabetic patients in modifying their lives. Considering this fact this study is intended to determine the prevalence and potential influential factors of diabetic foot ulcer among diabetic patients attending Arbaminch hospital diabetic clinic (Figure 1).

This conceptual frame work was developed after revision of various studies related to diabetes and diabetic foot ulcer. Variables in each box except the box containing diabetic foot ulcer were possible influential factors. The double arrow indicates the reverse effect of the one variable on the other. For example diabetic foot ulcer will be affect clients self care practice and vice versa.

\section{Methodology}

This Cross-sectional study was conducted in SNNP region of Ethiopia, Gamo Gofa zone, Arbaminch town, Arbaminch hospital. Arbaminch has two Sub cities, namely Secha and Sikela. Arbaminch town is located $505 \mathrm{Km}$ away from Addis Ababa, the capital of Ethiopia. The hospital is located in Secha which is the administrative center of Arbaminch town. Though Arbaminch hospital is technically a regional hospital, it is acting like a referral hospital. It serves more than 2 million people in the region. The hospitals annual patient flow is more than 100,000 . The following services are provided by the Hospital: Delivery service, Dental treatment, Emergency services, and Eye treatment, follow up services (chronic illness follow up), laboratory, OPD, pharmacy, Radiology \& Ward activities. Up to November 30-2012 three hundred diabetic patients are on follow up. This study was conducted from Feb.10, 2013 to April 10, 2013.

\section{Study population}

The present study included all patients diagnosed with diabetes and attending the hospitals diabetic follow-up clinic. According to the hospital Diabetes was diagnosed if the patients with a fasting plasma glucose level=,>126 mg/dl or a 2 -h post-glucose level after a 75 -g oral glucose tolerance test $=,>200 \mathrm{mg} / \mathrm{dl}$ plus suggestive clinical manifestations. Diabetic patients who have traumatic ulcer other than perceived risk factors such as car accident were excluded from the study.
For sample size determination, single population proportion statistical formula, considering $\alpha, 95 \%$ confidence interval, an expected prevalence $15 \%$ and $10 \%$ non response was used. The final sample size was 216. Diabetic patients', who were on follow up, card number was used as sampling frame. Simple random sampling technique was used to select those 216 diabetic patients.

Jimma university ethics and research committee approval was sough before starting the research. In addition to this informed consent was secured from the participants.

For data collection Structured medical record review guide, diabetic patients foot observation check list and structured patient interview questionnaire, adopted after reviewing different studies [5,914] were used. In order to collect data four Diploma level nurses with data collection experience were recruited considering their previous data collection experience, communication skill. Before the actual data collection one day training was given data collectors.

\section{Statistics}

The collected data was checked manually for its completeness. After this the data was coded and entered to epidata version 3.1 and then it was exported to SPSS version 16.0. Before the actual data analysis the data was explored for its completeness, outliers and missing values. Following data exploration descriptive statistical analysis was done for variables such as socio-demographic characteristics and clinical factors. For identification of independent variables which have association with the dependent variable, DFU, chi-square test and student t-test was used. All factors with $\mathrm{p}<025$ in the univariate analysis were considered as candidates for the multivariate regression model. The $95 \%$ confidence interval (CI) was calculated wherever found appropriate. P-value less than 0.05 of the multivariate analysis were considered significant (influential) factors.

\section{Operational definitions}

Diabetes self care attitude: Measured using statements related to diabetic self care. Likert scale of attitude measurement will be used to classify patients to sat have favorable attitude or unfavorable attitude towards diabetes self care.

Diabetic foot self care: Ability of the patient to perform self care activities that help the feet to be healthy

Neuropathy: is assessed and determined from the patient's medical history meaning the patient's medical card was reviewed for the presence of neuropathy

\section{Diabetic knowledge}

Knowledge of patients' relating to diabetes and self-care practice will be assessed by using 'yes/no' questions. A correct answer will be coded as ' 1 ' and an incorrect answer as ' 2 '; then score will be computed. Patients will be labeled as have knowledge of diabetes if the score is greater than the mean unless not knowledgeable (poor knowledge).

Attitude: Likert like scale was used to determine attitude of diabetic patients. Before attitude scoring negative statements were coded in the reverse way. If the score is $\geq$ the mean value for items of attitude he/she will be leveled as have unfavorable attitude

\section{Diabetic foot self care practice}

For diabetic foot self care self-care practices if the score is $\geq$ the mean value for items of self care practice he/she will be leveled as practice self care practice if not do not practice diabetic foot self care 
Citation: Deribe B, Woldemichael K, Nemera G (2014) Prevalence and Factors Influencing Diabetic Foot Ulcer among Diabetic Patients Attending Arbaminch Hospital, South Ethiopia. J Diabetes Metab 2: 322. doi:10.4172/2155-6156.1000322

Page 3 of 7

Diabetic foot ulcer: Non traumatic lesions of the skin (partial or full thickness) on the foot of a person who has diabetes mellitus.

\section{Results}

Two hundred sixteen diabetic patients were involved in the study of prevalence and factors influencing diabetic foot ulcer with the response rate one hundred percent. Diabetic foot ulcer was observed among 32 (14.8\%) diabetic patients. The mean age of the study population was $50.72 \pm 13.39$ years. With regard to gender distribution $129(59.7 \%$ were male. Considering place of residence $61(28.2 \%)$ was from rural area. One hundred sixty eight $(77.8 \%)$ were married. Corresponding to educational status $80(37 \%)$ have secondary education. Regarding age classification $38 \%$ were $48-57$ years. Almost thirty two percent of study populations were employs meaning they have paying job either from governmental or nongovernmental organizations.

Concerning knowledge about diabetes, 99(45.83\%) of client have good knowledge about diabetes. Diabetic foot self care practice was observed among 119(55.1\%) of clients. Pertaining to attitude towards diabetic foot self care 96(44.4\%) have favorable attitude. Considering body mass index majority of the study population lie within the range of $24.5-29.9 \mathrm{~kg} / \mathrm{m}^{2}$ that indicates they are overweight. Looking to the blood pressure, majority of the study population $183(84.7 \%)$ has systolic blood pressure less than $139 \mathrm{mmhg}$. With regard to diastolic blood pressure $41(19 \%)$ of the study population have DBP greater than $90 \mathrm{mmhg}$. Regarding fasting blood glucose level, the mean fasting blood glucose level among diabetic patients with foot ulcer is $177.97 \mathrm{mg} / \mathrm{dl}$ which is higher than those diabetic clients without diabetic foot ulcer.

Among the study population $23 \%$ were diabetic for more than 9 years and above .regarding to foot skin texture $31 \%$ have dry and cracked skin. Concerning to smoking status $13(6 \%)$ of the study populations were smokers. Among the study population 115(53.2\%) have chronic health problem or co- morbidity other than diabetes. Regarding use of ill fitting shoes majority of respondents use shoes that doesn 't fit their foot well. Sensation to vibration (often the first sense to be lost in peripheral neuropathy) using a relatively low-pitched tuning fork of $128 \mathrm{~Hz}$ was detected in 75(34.7\%) of the study population. Majority, $146(67.6 \%)$ of the study population has callus (Table 1 ).

\begin{tabular}{|l|l|c|c|c|c|c|}
\hline \multirow{2}{*}{ Variables } & & \multicolumn{2}{|c|}{$\begin{array}{c}\text { Diabetic } \\
\text { patients }\end{array}$} & & Sig. \\
\hline & & $\begin{array}{c}\text { without foot } \\
\text { ulcer }\end{array}$ & with foot ulcer & \\
\hline sex of the client & No & $\%$ & No. & $\%$ & \\
\hline & Female & 109 & 59.2 & 20 & 62.5 & 0.443 \\
\hline Residence & Urban & 75 & 40.8 & 12 & 37.5 & \\
\hline & Rural & 140 & 76.1 & 15 & 46.9 & 0.001 \\
\hline Educational & No education & 24 & $13 \%$ & 8 & 25 & 0.121 \\
\hline status & Primary education & 51 & 27.7 & 4 & 12.5 & \\
\hline & 2ry education & 66 & 35.9 & 14 & 43.8 & \\
\hline & Above 2ry education & 43 & 23.4 & 6 & 18.8 & \\
\hline & Single & 17 & 9.2 & 4 & 12.5 & 0.097 \\
\hline & Married & 148 & 80.4 & 20 & 62.5 & \\
\hline & Widowed & 13 & 7.1 & 6 & 18.8 & \\
\hline & Divorced & 6 & 3.3 & 2 & 6.2 & \\
\hline & & & & & 53.1 & \\
\hline
\end{tabular}

\begin{tabular}{|c|c|c|c|c|c|c|}
\hline \multirow[t]{6}{*}{ Age intervals } & $18-27$ & 9 & 4.9 & 0 & 0 & 0.038 \\
\hline & $28-37$ & 24 & 13 & 0 & 0 & \\
\hline & $38-47$ & 35 & 19 & 5 & 18.6 & \\
\hline & $48-57$ & 66 & 35.9 & 16 & 50 & \\
\hline & $58-67$ & 29 & 12.5 & 6 & 18.8 & \\
\hline & $68-77$ & 27 & 14.7 & 5 & 15.6 & \\
\hline \multirow[t]{6}{*}{ Occupation } & Employee & 65 & 35.3 & 3 & 9.4 & 0.002 \\
\hline & Farmer & 34 & 18.5 & 14 & 43.8 & \\
\hline & Merchant & 37 & 20.1 & 10 & 31.2 & \\
\hline & House wife & 27 & 14.7 & 5 & 15.6 & \\
\hline & Daily lobar & 5 & 2.7 & 0 & - & \\
\hline & Others & 16 & 8.7 & 0 & - & \\
\hline \multirow[t]{6}{*}{$\begin{array}{l}\text { Type of Co- } \\
\text { morbidity }\end{array}$} & Hypertension & 51 & 44.35 & 5 & 4.35 & 0.003 \\
\hline & Kidney disease & 12 & 10.4 & 7 & 6.1 & \\
\hline & Neuropathy & 14 & 12.2 & 9 & 7.8 & \\
\hline & Hypertension \& KD & 7 & 6.1 & 6 & 5.2 & \\
\hline & Others & 2 & 1.7 & 2 & 1.7 & \\
\hline & Total & 86 & 74.8 & 29 & 25.2 & \\
\hline \multirow[t]{2}{*}{ Dm knowledge } & Good knowledge & 85 & 85.85 & 14 & 14.15 & 0.81 \\
\hline & Poor knowledge & 96 & 84.21 & 18 & 15.79 & \\
\hline \multirow[t]{2}{*}{ Attitude } & Favorable & 88 & 91.67 & 8 & 8.33 & 0.02 \\
\hline & Unfavorable & 96 & 80 & 24 & 20 & \\
\hline \multirow[t]{2}{*}{$\begin{array}{l}\text { Dm self care } \\
\text { practice }\end{array}$} & Good self care & 107 & 89.9 & 12 & 11.1 & 0.54 \\
\hline & Poor self care & 77 & 79.38 & 20 & 20.62 & \\
\hline \multirow[t]{3}{*}{$\begin{array}{l}\text { Body Mass } \\
\text { Index (BMI) }\end{array}$} & $16-24.5$ & 72 & 94.73 & 4 & 5.67 & 0.003 \\
\hline & $24.5-29.9$ & 108 & 81.81 & 24 & 18.19 & \\
\hline & & 4 & 50 & 4 & 50 & \\
\hline \multirow[t]{2}{*}{$\begin{array}{l}\text { Systolic blood } \\
\text { pressure }\end{array}$} & $<140$ & 162 & 88.52 & 21 & 11.48 & 0.01 \\
\hline & $>,=140$ & 22 & 66.67 & 11 & 33.33 & \\
\hline \multirow[t]{2}{*}{ Diastolic BP } & $<90$ & 156 & 89.14 & 19 & 10.86 & 0.024 \\
\hline & $>=90$ & 28 & 68.29 & 13 & 31.67 & \\
\hline \multirow[t]{2}{*}{ Duration of DM } & $<10$ years & 154 & 90.96 & 12 & 9.04 & 0.001 \\
\hline & $>,=10$ years & 30 & 60 & 20 & 40 & \\
\hline \multirow[t]{2}{*}{ Foot skin texture } & Smooth and moist & 135 & 84.9 & 14 & 15.1 & 0.005 \\
\hline & Dry and /or cracked & 49 & 73.13 & 18 & 26.87 & \\
\hline \multirow[t]{2}{*}{$\begin{array}{l}\text { Sensory loss to } \\
\text { vibration }\end{array}$} & Absent & 129 & 91.48 & 12 & 8.52 & 0.001 \\
\hline & Present & 55 & 73.33 & 20 & 26.67 & \\
\hline \multirow[t]{2}{*}{$\begin{array}{l}\text { Use of ill fitting } \\
\text { shoes }\end{array}$} & Absent & 52 & 98.11 & 1 & 1.89 & 0.015 \\
\hline & Present & 132 & 80.89 & 31 & 19.02 & \\
\hline \multirow[t]{2}{*}{ Callus of the feet } & Absent & 115 & 78.76 & 31 & 21.24 & 0.004 \\
\hline & Present & 69 & 98.57 & 1 & 1.43 & \\
\hline $\begin{array}{l}\text { Mean FBS in } \\
\mathrm{mg} / \mathrm{dl}\end{array}$ & $131.62 \pm 32.08$ & & & $177 \pm 35.45$ & & 0.035 \\
\hline
\end{tabular}

${ }^{* *}$ Employed "those peoples working as professional in either in governmental or nongovernmental organizations"

Table 1: Demographic variables among diabetic patients with and without foot ulcer, Arbaminch, south Ethiopia April 2013. 
Citation: Deribe B, Woldemichael K, Nemera G (2014) Prevalence and Factors Influencing Diabetic Foot Ulcer among Diabetic Patients Attending Arbaminch Hospital, South Ethiopia. J Diabetes Metab 2: 322. doi:10.4172/2155-6156.1000322

Page 4 of 7

\section{Factors influencing diabetic foot ulcer}

Callus of the foot makes diabetic patients 18.6 times more likely to have DFU as compared to diabetic patients without callus on the foot $(\mathrm{OR}=18.6,95 \%$ CI 2.48, 139). Diabetic patients with loss of sensation to vibration of $128 \mathrm{~Hz}$ of tuning forke were 3.91 times more likely to have DFU as compared to those without sensory lose $(\mathrm{OR}=3.91,95 \% \mathrm{CI}$ $1.78,8.54)$. If all the factors are kept constant, diabetic patients using ill Fitting shoes were 12.2 times more likely to have foot ulcer as compared to those who do not use ill fitting shoes(OR=12.2, 95\% CI 1.6-91.7). Patients from rural area are 3.6 times more likely to develop diabetic foot ulcer compared to those from urban area $(\mathrm{OR}=3.6,95 \% \mathrm{CI} 1.66$, 7.81). Regarding foot skin texture the odds in favor of having diabetic foot ulcer among those diabetic patients with dry and cracked foot skin are 3.5 times higher as compared to those with smooth and moist foot skin $(\mathrm{OR}=3.5,95 \% \mathrm{CI} 1.63,7.65)$. The odds ratio for co-morbidity indicates that, when holding all other factors constant diabetic patients with co morbidity are 7.8 times more likely to have foot ulcer than those who don `t have co-morbidity(OR= 7.8, 95\% CI 2.63, 23.14).

Controlling all other factors constant, overweight diabetic patients (BMI $24.5-29.9 \mathrm{~kg} / \mathrm{m}^{2}$ ) are 4 times more likely to have DFU as compared to those diabetic patients with normal body mass index (16.5-24.5 kg/ $\left.\mathrm{m}^{2}\right)(\mathrm{OR}=4,95 \% \mathrm{CI} 1.332,12.01)$. Patients with hypertension were selected as reference group because of their abundance. Keeping all other factors constant patients with neuropathy were 4.68 times more likely to develop diabetic foot ulcer than diabetic patients with hypertension $(\mathrm{OR}=4.68,95 \% \mathrm{CI} 1.48,14.8)$.

Rural residence increases the chance of having DFU by factor of 4.074 as compared urban residence (AOR 4.07, 95\% CI 1.262-13.151). Farmer diabetic patients were 6.54 times more likely to develop diabetic foot ulcer as compared to employees of either government or non government organizations (AOR 6.542, 95\% CI 2.841-49.035). The odds in favor of DFU increases by 5.11 times for diabetic patients with mean arterial blood pressure greater than 90 compared to those whose mean arterial blood pressure is less than 90 (AOR=5.113, 95\%CI 1.285-20.347). The odds in favor of developing diabetic foot ulcer was $38.9 \%$ less likely in patients without chronic co-morbidity as compared to those with chronic co morbidity (AOR $=0.611,95 \% \mathrm{CI} 0.131-0.955$ ). Diabetic patients with duration of diabetes more than 10 years are 8.452 times more likely to develop diabetic foot ulcer as compared to those duration of diabetes is less than 10 years (AOR, 8.452, 95\% CI 2.305, 30.994) (Table 2).

\begin{tabular}{|c|c|c|c|c|c|}
\hline \multirow[t]{2}{*}{ Factors } & & \multicolumn{2}{|l|}{ foot ulcer } & \multirow[t]{2}{*}{ COR(95\% Cl) } & \multirow[t]{2}{*}{ AOR(95\% CI) } \\
\hline & & present & Absent & & \\
\hline \multirow[t]{2}{*}{ Foot skin texture } & Dry \& craked & 18 & 49 & $3.5(1.63,7.65)$ * & \\
\hline & Smooth \& moist & 14 & 135 & 1 & \\
\hline \multirow[t]{2}{*}{ Callus of the feet } & Present & 31 & 69 & $18.6(2.48,139)$ * & $9.542(0.889,102.444)$ \\
\hline & Absent & 1 & 115 & 1 & 1 \\
\hline \multirow[t]{2}{*}{ Usse of ill fiiting shoe } & Yes & 31 & 132 & $12.2(1.62,9.17)$ * & \\
\hline & No & 1 & 52 & 1 & \\
\hline \multirow[t]{2}{*}{ Sensory loss to vibration } & Present & 20 & 55 & $3.91(1.78,8.54)$ * & \\
\hline & Absent & 12 & 129 & 1 & \\
\hline \multirow[t]{2}{*}{ Residence } & Urban & 15 & 140 & 1 & 1 \\
\hline & Rural & 17 & 44 & $3.6(1.66,7.81)$ * & $4.074(1.262,13.151)$ ** \\
\hline \multirow[t]{2}{*}{ Age in years } & $<45$ & 4 & 57 & 1 & \\
\hline & $\geq 45$ & 28 & 127 & $3.142(1.053-9.375)$ * & \\
\hline \multirow[t]{4}{*}{ Occupation } & Employees & 3 & 65 & 1 & 1 \\
\hline & Farmers & 14 & 34 & $7.92(2.397,33.202)$ * & $6.542(2.841,49.035)$ ** \\
\hline & Merchant & 10 & 37 & $5.86(1.515,22.631)$ * & $5.349(0.766,37.346)$ \\
\hline & Housewife & 5 & 27 & $4.02(0.895,17.98)$ & $3.353(0.368,30.579)$ \\
\hline \multirow[t]{11}{*}{ Co-morbiditiy } & yes & 28 & 87 & $7.8(2.63,23.14)$ * & 1 \\
\hline & No & 4 & 97 & 1 & $0.611(0.131,0.955)$ ** \\
\hline & $\geq 90$ & 20 & 72 & $2.59(1.195,5.652)$ * & $5.113(1.285,20.347)$ ** \\
\hline & $<90$ & 12 & 112 & 1 & 1 \\
\hline & $\geq 10$ years & 20 & 30 & $8.56(3.785,19.34)$ * & $8.452(2.305,30.994)$ ** \\
\hline & $<10$ years & 12 & 154 & 1 & 1 \\
\hline & Faverable & 8 & 88 & 1 & \\
\hline & Unfaverable & 24 & 96 & $2.75(1.174,6.439)$ * & \\
\hline & Good practice & 12 & 107 & 1 & \\
\hline & Poor practice & 20 & 77 & $2.32(1.059,5.019)$ * & \\
\hline & $16.5-24.5$ & 4 & 72 & 1 & \\
\hline
\end{tabular}




\begin{tabular}{|l|c|c|c|c|}
\hline & $24.5-29.5$ & 24 & 108 & $4.0(1.332,12.01)^{*}$ \\
\hline & $\geq 29.5$ & 4 & 4 & $18.0(3.246,99.82)^{*}$ \\
\hline & Hypertension & 7 & 51 & 1 \\
\hline & kidney disease & 7 & 12 & $4.25(1.25,14.42)^{*}$ \\
\hline & Neuropathy & 9 & 14 & $4.68(1.48,14.8)^{*}$ \\
\hline & HPN \& kidney disease & 6 & 7 & $6.24(1.62,24.01)^{*}$ \\
\hline
\end{tabular}

Note: * variable with $\mathrm{p}$ value of $<0.05$ in univariate analysis ** statistically significant associations in ultivariate analysis. ' 1 ' reference group, AOR stands for adjusted odds ratio, COR stands for crud (unadjusted) odds ratio.

Table 2: Factors associated with diabetic foot ulcer among diabetic patients attending Arbaminch hospital diabetic clinic, Arbaminch south Ethiopia, 2013.

\section{Discussion}

This study shows that significant number of diabetic patients (14.8\%) coming to Arbaminch Hospital diabetic follow up clinic have DFUs. According to standard books this prevalence is within the reference range. The possible explanation for this high prevalence of DFU among diabetic patients of Arbaminch might be related to diabetic foot self care practice, health seeking behavior and diabetes related knowledge of patients. Besides significant number of patients were coming from far rural areas which are far away from the hospitals catchment area. Besides our study's result flashed the need to do lots of job to prevent diabetic foot ulcer. Previous studies in different areas have reported the prevalence of DFUs in the range of 4.6-11.9\% among diabetic patients $[2,15,16]$. The difference might be due to variation in sample size, study population, study area or it may be explanation of sociocultural variation of the study participants. In spite of that, this study finding was comparable with the study conducted in North India [13] and Nigeria [17].

The occurrence of DFUs mostly in males and middle aged subjects has been reported by several researchers [18-20]. Those figures have slight variation with the present finding. This may be reflection of regional variation in the prevalence of diabetes mellitus and locally operating factors like sociodemographic and sociocultural variables. This study found, $62.5 \%$ of males and $37.5 \%$ of females with a mean age of 55.81 years having DFUs and this is consistent with the findings of previous works $[13,19,21]$. The variation of DFU related to sex and age, might be reflection of variation in societal role between male and females in southern Ethiopia, typically in the study area, males spent most of their time outside homes doing jobs that need more energy compared to women. The increase in DFUs among diabetic patients, particularly in our study area, is worrying situation for individual families as males are the backbone and the sole earning members of the family, particularly in south Ethiopian population.

This study which is aimed to assess the prevalence and factors affecting diabetic foot ulcer found that $53.1 \%$ of diabetic patients with foot ulcer were from rural and the remaining $42.1 \%$ were from urban area. This is consistent with recent study conducted in India that found high prevalence of foot ulcer among diabetic patients from rural area [13]. The association between residence and diabetic foot ulcer may be due to the fact that individuals in rural areas of Ethiopia particularly in the study area often spent most of their time in farm area or outdoors. These people are commonly subject to rodent bites, especially bites to the feet of patients with diabetes can lead to ulceration due to poor healing.

The odds in favor of DFU for overweight diabetic patients were four times more likely as compared to diabetic patients who were not overweight. Body weight and body mass index were emerged as an influential factors for developing diabetic foot ulcer, with higher risk associated with greater weight and increased body mass index [17]. One potential mechanism for this association might be higher foot pressure in heavier and those with higher BMI subjects.

Long duration of diabetes, even after controlling for age, was a statistically significant finding in several studies [13,22]. This crossectional study also found that the odds in favor of having diabetic foot ulcer is increased by 8 times higher in those who were diabetic for more than 10 years as compared to those whose duration of diabetes is less than 9 years which is comparable with previous studies $[13,23,24]$. The possible explanation might be the fact that diabetic patients for long time were presumed to be at more risk due to the development of long term diabetic complications such as peripheral vascular disease (PVD), neuropathy, nephropathy and retinopathy which could lead to the occurrence of foot ulcer in the diabetic patients.

This crossectional study identified use of ill fitting shoes as an influential factor for the development of diabetic foot ulcer which is in line with study conducted in black line hospital, Ethiopia [25]. This increased risk among those who uses ill fitting shoes might be related to high chance and frequency of foot injury which may result in subsequent ulceration.

Though this is the first study to identify the prevalence and influential factors of DFU using Interview administered questioner, patient medical record review and foot observation check list, it has certain limitations .it would have been better if prospective cohort study have been conducted to identify the real life determinants. Besides there may be recall bias on recalling duration of illness, self reporting of patients regarding diabetic foot self care practice and accuracy of measuring instruments like BP apparatus is questionable.

\section{Conclusion}

The prevalence of diabetic foot ulcer among diabetic patients in Arbaminch hospital was $14.8 \%$. This study con-firm that foot ulcers in diabetes result from multiple influential factors. Significant influential factors were rural residence, mean arterial blood pressure, Comorbidity, occupation and duration of diabetes.

\section{Recommendations}

Based on the study finding the following recommendations are drown to reduce the prevalence of DFU and its associated unwelcomed effects.

- Even though the prevalence of diabetic foot ulcer is within the expected range, Gamo Gofa zone health sector and Arbaminch hospital diabetic clinic diabetic care providers should strive to reduce its prevalence through enhancing the knowledge, diabetic self care practice and regular diabetic foot evaluation.

- In addition to the routine care, especial emphasis should be 
Citation: Deribe B, Woldemichael K, Nemera G (2014) Prevalence and Factors Influencing Diabetic Foot Ulcer among Diabetic Patients Attending Arbaminch Hospital, South Ethiopia. J Diabetes Metab 2: 322. doi:10.4172/2155-6156.1000322

Page 6 of 7

given by treating health care provider for patients coming from rural area, those with co-morbidity and sensory loss.

- To minimize the risk of developing diabetic foot ulcer, Health educators should emphasize on the benefit of weight reduction, blood pressure monitoring and avoiding wearing of ill fitting shoes.

- Further prospective study is recommended to identify the real life determinants of diabetic foot ulcer.

\section{Authors' Contribution}

$\mathrm{BD}$ wrote the proposal, participated in data collection, analyzed the data and drafted the paper. KW and GN participated by revising and approving the proposal, data analysis and revised subsequent drafts of the paper. SE has been involved in drafting the manuscript. All authors read and approved the final manuscript.

\section{Authors' Information}

$\mathrm{BD}$ is lecturer in department of nursing of Jimma University, KW is professor of epidemiology in college of public health and medicinal science of Jimma University and GN is senior lecturer in Jimma university department of nursing and nursing service director in Jimma University specialized hospital. All authors are currently staff members in their respective departments in Jimma University.

\section{Acknowledgment}

We would like to thank Jimma University for providing fund to conduct the study. We would also like to forward our gratitude to all data collectors, facilitator and study participants involved in this study.

\section{References}

1. Wild S, Roglic G, Green A, Sicree R, King H (2004) Global prevalence of diabetes: estimates for the year 2000 and projections for 2030. Diabetes Care 27: 1047-1053.

2. International Diabetes Federation (2012) The Global Burden. IDF Diabetes Atlas Fifth Edition.

3. Alvin C (2005) Diabetes mellitus. Harrison T (edn) Principle of internal medicine (16 ${ }^{\text {th }}$ edn), New York. McGraw-Hill Companies: 830-835.

4. Vileikyte L (2001) Diabetic foot ulcers: a quality of life issue. Diabetes Metab Res Rev 17: 246-249.

5. Reiber GE, Boyko E, Smith DG (1995) Lower extremity ulcers and amputations in individuals with diabetes. In Diabetes in America ( $2^{\text {nd }}$ edn), Harris MI (ed.), National Institutes of Health Publication No. 95-1468.

6. Leung PC (2007) Diabetic foot ulcers--a comprehensive review. Surgeon 5: 219-231.

7. Amogne W, Reja A, Amare A (2011) Diabetic foot disease in Ethiopian patients: A hospital based study. Ethiopia J Health Dev 25: 17-21.

8. WHO (2006) Core health indicators: the latest data from multiple WHO sources. United Republic of Tanzania. Geneva: World Health Organization.

9. Robert A (2011) The Awareness and Performance of Appropriate Foot SelfCare Practices Among Diabetic Patients Attending Dr. Yusuf Dadoo Hospital, Gauteng Province, South Africa.

10. Insight Health Economics (2012) Foot Care for People with Diabetes: The Economic Case for Change.
11. Apelqvist J, Bakker $\mathrm{K}$, van Houtum $\mathrm{WH}$, Nabuurs-Franssen $\mathrm{MH}$, Schaper NC (2000) International consensus and practical guidelines on the management and the prevention of the diabetic foot. International Working Group on the Diabetic Foot. Diabetes Metab Res Rev 16 Suppl 1: S84-92.

12. Pecoraro RE, Reiber GE, Burgess EM (1990) Pathways to diabetic limb amputation. Basis for prevention. Diabetes Care 13: 513-521.

13. Shahi SK, Kumar A, Kumar S, Singh SK, Gupta SK, et al. (2012) Prevalence of Diabetic Foot Ulcer and Associated Risk Factors in Diabetic Patients From North India. The Journal of Diabetic Foot Complications 4: 83-91.

14. Vincent Lopez Rowe. Diabetic Ulcers.

15. Palumbo PJ, Melton III LJ (1985) Peripheral vascular disease and diabetes. In Diabetes in America, Harris MI, Hammon RF (eds). US Government Printing Office: Washington.

16. Boulton AJM (1993) The diabetic foot. Medicine International: 271-274.

17. Unachukwu C, Babatunde S, Ihekwaba AE (2007) Diabetes, hand and/or foot ulcers: a cross-sectional hospital-based study in Port Harcourt, Nigeria. Diabetes Res Clin Pract 75: 148-152.

18. Hitman G, Chowdhury $T$ (2007) Diabetes and other metabolic disorders. In: Michael S, Michael G (eds). Hutchison's clinical methods, Elsevier: 280-292.

19. Assal JP, Mehnert H, Tritschler HJ, Sidorenko A, Keen H; Hellmut Mehnert Award Workshop Participants (2002) On your feet! Workshop on the diabetic foot. J Diabetes Complications 16: 183-194.

20. Nyamu PN, Otieno CF, Amayo EO, McLigeyo SO (2003) Risk factors and prevalence of diabetic foot ulcers at Kenyatta National Hospital, Nairobi. East Afr Med J 80: 36-43.

21. Ogbera AO, Fasanmade O, Ohwovoriole AE, Adediran O (2006) An assessment of the disease burden of foot ulcers in patients with diabetes mellitus attending a teaching hospital in Lagos, Nigeria. Int J Low Extrem Wounds 5: 244-249.

22. Snyder RJ, Hanft JR (2009) Diabetic foot ulcers--effects on QOL, costs, and mortality and the role of standard wound care and advanced-care therapies. Ostomy Wound Manage 55: 28-38.

23. Khan H, Khan Z, Khan I, Jamal ud Din, Rehman S, Khan B (2011) Factors contributing to the development of diabetic foot ulcers and role of health literacy. RMJ 36: 34-37.

24. Manda V, Sreedharan J, Muttappallymyalil J, Das R, Hisamatsu E (2012) Foo ulcers and risk factors among diabetic patients visiting Surgery Department in a University Teaching Hospital in Ajman, UAE. International Journal of Medicine and Public Health 2: 34-38.

25. Larsson J (1994) Lower extremity amputation in diabetic patients. Doctoral thesis, Lund University, Lund, Sweden. 